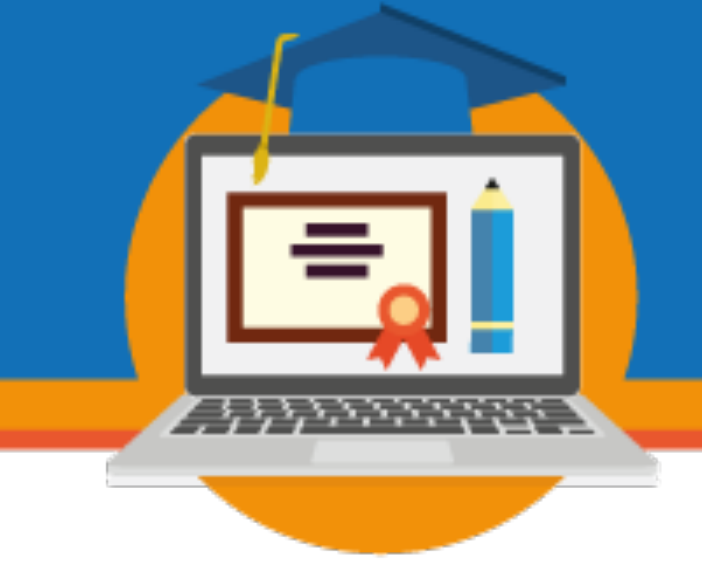

\title{
A DIALOGICIDADE ENTRE TUTOR E ALUNO EM EAD NA PERSPECTIVA DE PAULO FREIRE: A VISÃO DO DISCENTE
}

\author{
Adriane das Neves Silva \\ . Docente Colégio Estadual Hilton Gama. Mestre em Ensino na Saúde da Universidade \\ Federal Fluminense (UFF), Especialista em EAD (UFF). RJ-Brasil. E-mail: \\ adrianeneves@bol.com.br. \\ Cynthia das Neves Silva \\ Enfermeira. Professor SENAC-RJ. Especialista em Emergência (UFF). Especialista em \\ Pediatria (UGF). RJ-Brasil. E- mail: cynthia.das@bol.com.br
}

\begin{abstract}
Solange das Neves Silva
Enfermeira. Professora Colégio Mercúrio. Especialista em Emergência (UFF). Especialista em Enfermagem do Trabalho (Faculdade Souza Marques). RJ-Brasil. E-mail: sn.silva1967@bol.com.br
\end{abstract}

Samuel Gonçalves Pinto

Pedagogo. Profissional de Educação Física. Coordenador do Curso de Educação Físca da FUPAC/Ponte Nova-MG. Doutor em Ciências do Esporte e Atividade Física (UERJ). E-mail: samuel.pto@gmail.com

Eixo 04: Trabalho docente e Processos Didáticos na EaD

\begin{abstract}
RESUMO
O tema central desse trabalho é analisar de que forma a aprendizagem dialógica proposta por Paulo Freire pode contribuir como facilitadora da aprendizagem, tentando verificar novas metodologias de ensino, bem como as competências e saberes inerentes ao educador na função de professor/tutor e do aluno na modalidade de Ensino a Distância. Como metodologia foi adotada uma pesquisa descritivo-exploratória com abordagem qualitativa. Assim, como o estudo podem-se identificar as contribuições da relação dialógica nas propostas de educação à distância na perspectiva de Paulo Freire. As ferramentas interativas favorecem a aprendizagem colaborativa e o diálogo, o que não garante que as mesmas por si só contribuem para o êxito dos programas a distância, sendo necessário um planejamento de como serão utilizadas as ferramentas interativas. Conclui-se que o diálogo proporcionou um caminho favorável para efetividade das ações no curso, pois quando a interação é pautada no diálogo, trazendo a proposta de valorizar e socializar o conhecimento trazido pelo aluno como eixo do processo de ensino-aprendizagem estará promovendo a construção participativa do conhecimento.
\end{abstract}




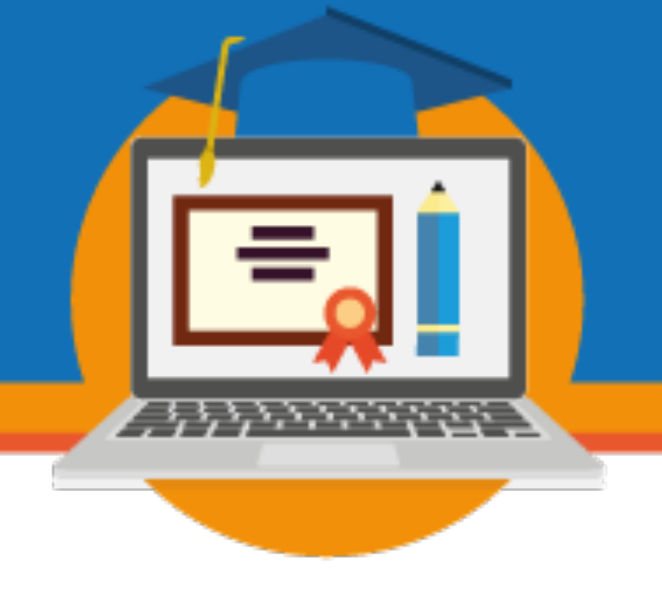

Palavras-chaves: educação a distância, Paulo Freire, ensino-aprendizagem, educação dialógica, tecnologia Educacional.

\section{INTRODUÇÃO}

As constantes mudanças no cenário da educação nos últimos tempos têm caminhado para uma nova concepção de aprender-ensinar, onde os papeis dos indivíduos envolvidos nesse processo sofrem grandes mudanças. Percebemos então a necessidade de romper com os paradigmas tradicionais e abrir o olhar para novas ações. Como diz Freire (2004) apud Ribas (2010): “ninguém nos ensina a fazer essas coisas, mas também não aprendemos a fazê-las sozinhos. Aprendemos a fazê-las interagindo com os outros". O diálogo é o elemento fundamental para a prática educativa.

Como bem ressaltou Ribas (2010) é importante entender o diálogo como elemento fundamental da relação pedagógica, que traz na estreita relação com os pressupostos freireanos, a importância de conhecer o aluno como agente do processo pedagógico, de entender a valorização do saber do educando.

A relação entre os seres é à base do diálogo e da interação, o que implica dizer que de um lado temos a dialogicidade e conscientização e do outro a interação, conforme diz Sabattini (2013, p. 6), que a dialogicidade, aparece como uma das principais justificativas da modalidade Educação à distância.

Sabemos que a aprendizagem autônoma depende em parte do professor conceber o aluno como um ser ativo, capaz de formular hipóteses, estabelecer conceitos e conjecturar teorias, construindo assim, seu próprio conhecimento - neste sentido a sua relação pedagógica muda: não cabendo mais a este aluno a posição de mero receptor de "conhecimentos", onde o professor é o detentor do saber e responsável por transmitir conteúdos já prontos a um aluno passivo que não reflete acerca do que "aprende", mas sim conceber o discente como um agente 


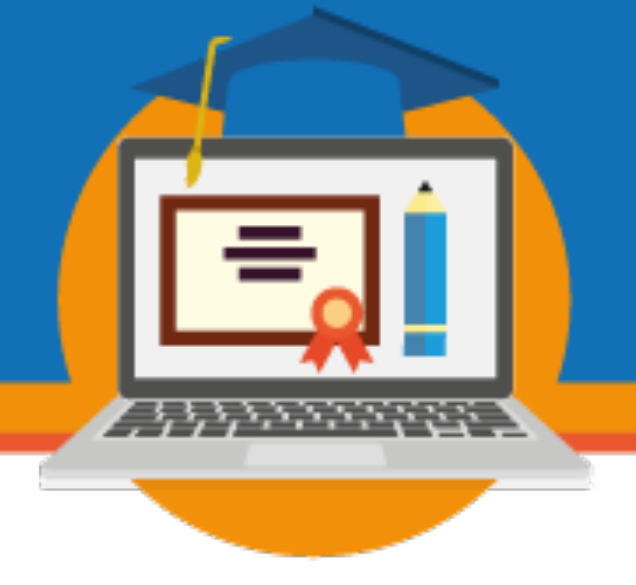

ativo de seu aprendizado, ou seja, é o momento do conhecimento sendo criado/recriado até a sua sedimentação.

O processo de ensino aprendizagem em Educação a Distância traz em si peculiaridades especificas desta modalidade. As formas de interação aluno-tutor/tutor-aluno, a forma como o processo de aprendizagem ocorre, as praxes didático-pedagógicas utilizadas ao longo dos cursos, bem como os recursos de apresentação dos conteúdos e avaliação são algumas das questões a serem analisadas neste trabalho. Sendo assim, temos como objetivo geral analisar de que forma a aprendizagem dialógica proposta por Paulo Freire pode contribuir como facilitadora da aprendizagem, tentando verificar novas metodologias de ensino, bem como as competências e saberes inerentes ao educador na função de professor/tutor e do aluno na modalidade de Ensino a Distância.

\section{METODOLOGIA}

Trata-se de uma pesquisa descritivo-exploratória com abordagem qualitativa, que tem a intenção de analisar de que forma a aprendizagem dialógica proposta por Paulo Freire pode contribuir como facilitadora da aprendizagem, tentando verificar novas metodologias de ensino, bem como as competências e saberes inerentes ao educador na função de professor/tutor e do aluno na modalidade de Ensino a Distância.

O público alvo desta pesquisa foram 20 profissionais discentes de um curso pósgraduação em Ativação de Processos de Mudanças na Formação Superior em Saúde ministrado pela Escola Nacional de Saúde Pública (ENSP), tendo como foco o questionamento do conceito de Dialogicidade, tanto na teoria quanto na prática da $\mathrm{EaD}$, bem como as práticas didático pedagógicas adotadas pelos tutores nesses cursos.

O instrumento para coleta de dados foi um questionário, onde as perguntas tiveram um caráter investigativo no que tange o processo educacional da $\mathrm{EaD}$, ou seja, questionamos as impressões dos discentes quanto a importância da relação dialógica no exercício da tutoria em EaD. Serão questionados aspectos como: o uso da modalidade em termos de formação pessoal; 


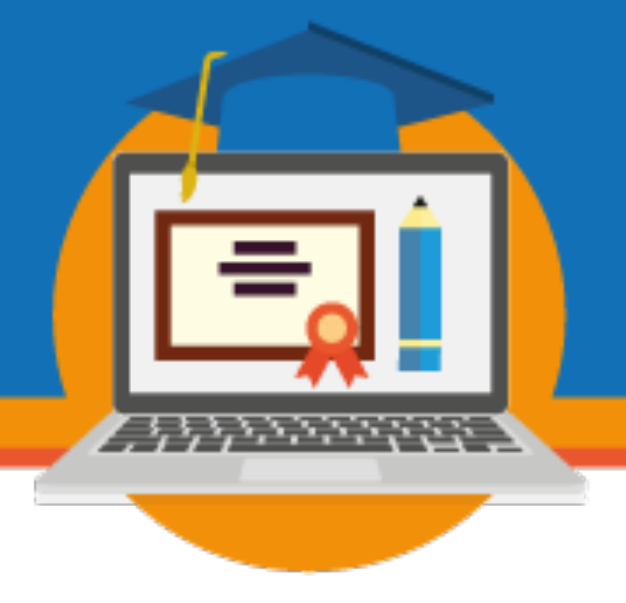

o conhecimento da Teoria Freiriana e do conceito de Dialogicidade; o impacto (positivo e negativo) da ação do tutor (positivo quando este se faz presente e acompanha o aluno; negativo quando o aluno não tem o suporte necessário que o tutor deveria prestar); a capacidade, sob o ponto de vista dos alunos se adaptarem à modalidade e efetivamente adquirirem aprendizado, ao fazer uso da tutoria; as dificuldades do aluno no processo, além do uso de metodologias ativas no $\mathrm{EaD}$.

\section{RESULTADOS}

Para organização e visualização da análise realizou-se a demonstração das tabelas de acordo com a divisão temática do questionário.

A análise foi desmembrada em duas partes assim como se efetuou no questionário:

- Conhecimentos prévios em $\mathrm{EaD}$, formação e capacitação;

- Uso de ferramentas interativas e;

- $\quad$ Preceitos de dialogicidade e autonomia.

TABELA 1

Formação/capacitação anterior dos discentes

\begin{tabular}{|l|c|c|}
\hline Formacáo/capacitacio & Quantidade & Porcentagem (86) \\
\hline Sim & 06 & 30 \\
\hline Nấo & 14 & 70 \\
\hline Total & 20 & 100 \\
\hline
\end{tabular}

De acordo com os resultados apresentados $70 \%$ dos discentes não realizaram alguma formação antes de iniciar as suas atividades. A partir disso, entende-se que a falta de formação/capacitação anterior em $\mathrm{EaD}$ foi um dificultador, pois a inabilidade de lidar com a tecnologia cria dificuldades de acompanhar as propostas dos cursos em EaD. Corroborando com Mercado (2007), que a EaD baseada nas tecnologias requer uma alfabetização tecnológica que pode se tornar um obstáculo. $\mathrm{Na} \mathrm{EaD}$, os alunos experimentam uma série de dificuldades e 


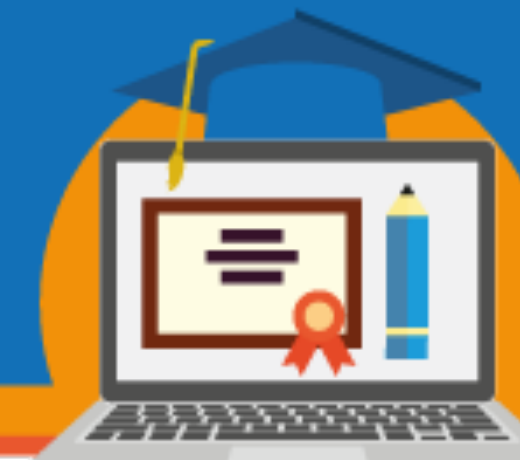

necessidades por não contarem com a experiência prévia, nem as habilidades necessárias para enfrentar com êxito esta modalidade de estudo.

A análise do uso de ferramentas interativas a partir das concepções discentes foi apresentada nas tabelas 2 e 3 , quais as mais utilizadas e se favorecem a interatividade/comunicação.

TABELA 2

Ferramentas interativas utilizadas pelos discentes

\begin{tabular}{|l|c|}
\hline Ferramentas interativas & Quantidade de respostas \\
\hline Fórum & 20 \\
Chat & 20 \\
Wiki & 01 \\
Agenda/mural & 14 \\
Biblioteca & 14 \\
Mensagem/correio & 11 \\
Tarefas & 05 \\
\hline Enquetes & 01 \\
\hline Glossário & 0 \\
\hline Total de discentes & 20 \\
\hline
\end{tabular}

TABELA 3

Favorecimento das ferramentas interativas utilizadas na EaD de acordo com os discentes

\begin{tabular}{|l|c|c|}
\hline Ferramentas favorecem a & Quantidade & Porcentagem (\%) \\
interatividade na EaD & 12 & 60 \\
\hline Sim & 0 & 0 \\
Năo & 8 & 40 \\
\hline Parcialmente & 20 & 100 \\
\hline Total
\end{tabular}

A partir da tabela 2, pode-se verificar tanto a utilização das ferramentas assíncronas (fóruns) e síncronas (chats), que são usadas com frequências nos cursos em EaD, porém na

\section{SEMINÁRIO DE EDUCAÇÃO A DISTÂNCIA}

Diálogos sobre EaD e uso das TDIC na educação: regulamentação em tempos recentes

3 a 6 de novembro de 2020 - Brasília/DF - Online 


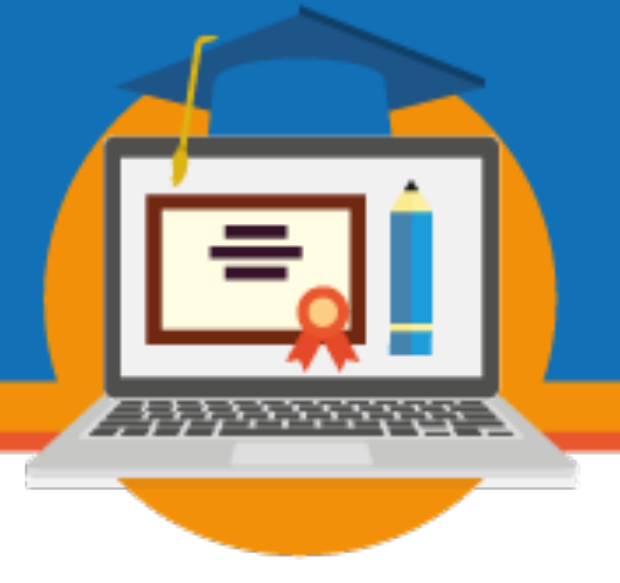

opção aparecem também outras ferramentas ou mídias, como: wiki, agenda/mural, biblioteca, mensagem/correio, tarefas e enquetes.

Podemos perceber que a utilização das ferramentas possibilita interações, que permite a criação de elos comunicativos durante o processo educacional. Como ressalta Fuks et al (2004) as ferramentas interativas são aquelas utilizadas para facilitar o processo de ensinoaprendizagem e estimular a colaboração e interação entre os participantes de um curso baseado na web.

Para Belloni (2006) interatividade são mecanismos que potencializam o diálogo entre as partes com vistas a intervenção, o diálogo para construção coletiva do conhecimento, portanto, no estudo aparece que entre os discentes a percepção da importância das ferramentas e a potencialização das mesmas no promoção do diálogo é clara.

A tabela 3 mostra outro aspecto importante a ser considerado, onde para $60 \%$ dos discentes as ferramentas utilizadas no curso favorecem a interatividade e a comunicação na EaD e para $40 \%$ dos discentes são parcialmente favoráveis. A interação nos cursos em EaD, seja ela síncrona ou assíncrona, favorece a motivação do aluno e auxilia o aprendizado, a medida que haja feedback do tutor, pois ele proporciona condição necessário para essa interação. A demora do feedback é um ponto negativo para a efetividade dessa interatividade, pois o aluno perde o interesse e a interação não se completa. Conforme sugere Freire (2006) ao discorrer que a educação dialógica deve ser fomentadora da problematização e da colaboração, portando o diálogo deve ser problematizador.

Nas tabelas 4 e 5, procurou-se evidenciar a relação entre o uso das ferramentas com o tutor e o aluno, e ainda verificar se houve favorecimento da aprendizagem colaborativa. 


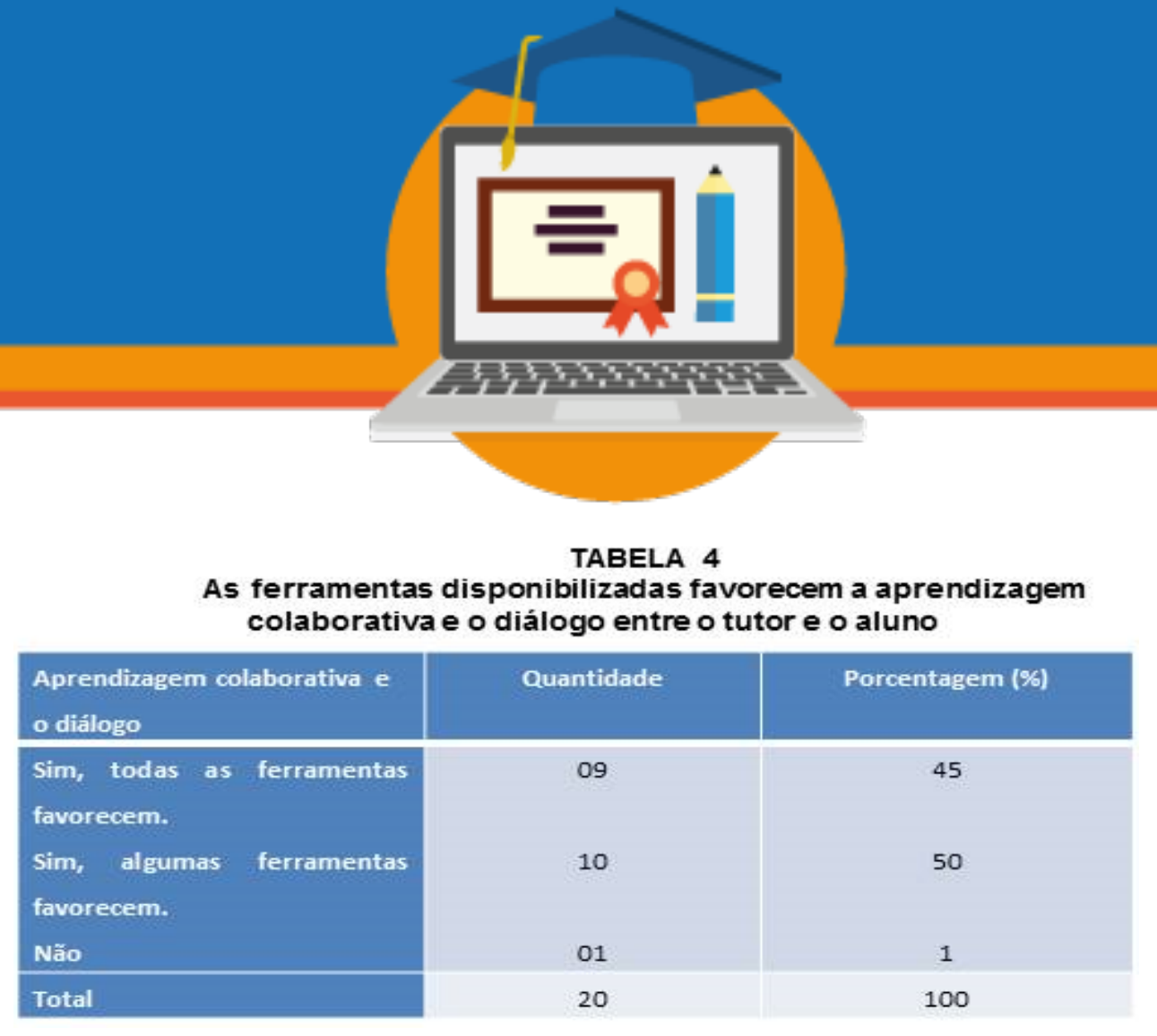

A partir da leitura dos dados apresentados na tabela 4 , a maioria dos discentes acreditam que as ferramentas favorecem a aprendizagem colaborativa e o diálogo entre tutor e aluno. À medida que a interação é fortalecida há potencialização da aprendizagem colaborativa e do diálogo. Conforme ressalta Kenski (2006) à interação pressupõe envolvimento e interagir com informações e pessoas para aprender. Sendo assim, a medida que a interação é fortalecida há potencialização da aprendizagem colaborativa e do diálogo. Ainda corroborando com Freire (2002), o aluno deve ser estimulado à construção do seu próprio conhecimento, o que nos leva a ver a importância das ações do tutor no estabelecimento da relação dialógica.

A questão sobre a contribuição das ferramentas interativas favorecendo a autonomia do aluno é de suma importância quando se pensa nos preceitos de Paulo Freire e é analisada na tabela 5 .

TABELA 5 Autonomia do aluno propiciada pelo uso das ferramentas interativas

\begin{tabular}{|l|c|c|}
\hline Autonomia & Quantidade & Porcentagem (\%) \\
\hline Sim & 16 & 80 \\
\hline Näo & 01 & 5 \\
\hline Talvez & 03 & 15 \\
\hline Total & 20 & 100 \\
\hline
\end{tabular}

A partir da leitura dos resultados na tabela 5, pode-se perceber que para a maioria dos discentes as ferramentas utilizadas favorece a autonomia do aluno. Conforme Paulo Freire, o 


\section{$=1$

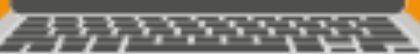

desenvolvimento da autonomia se faz na relação entre os seres por meio de ações dialógicas, onde ao ser estimulado o sujeito é tocado onde através da mediação a aprendizagem nos espaços de aprender e ensinar se torna significativa.

A autonomia que o ambiente permitiu trazer a responsabilidade pelo seu aprendizado, entendendo o sujeito como elemento imprescindível na relação pedagógica (Silva, 2014), mostra o que há de comum entre o pensamento de Paulo freire e a Educação a Distância, em que há respeito ao saber do educando, de suas experiências, permitindo a construção do conhecimento (FREIRE, 2006).

No que concerne aos preceitos da dialogicidade propostos por Freire e a utilização das metodologias ativas na EaD, será mostrada a seguir, por meio das tabelas 6, 7 e 8, qual o conhecimento do discente sobre dialogicidade e suas contribuições para a EaD e, se as metodologias ativas contribuem para a autonomia do aluno.

TABELA 6

Conhecimento da dialogicidade de Paulo Freire

\begin{tabular}{|l|c|c|}
\hline Dialogicidade & Quantidade & Porcentagem (\%) \\
\hline Sim & 09 & 45 \\
\hline Näo & 01 & 5 \\
\hline Em parte & 10 & 50 \\
\hline Total & 20 & 100 \\
\hline
\end{tabular}

TABELA 7

A Dialogicidade contribui para a $\mathrm{EaD}$

\begin{tabular}{|l|c|c|}
\hline Dialogicidade contribui para & Quantidade & Porcentagem (\%) \\
\hline a EaD & 12 & 60 \\
\hline Sim & 0 & 0 \\
Năo & 04 & 20 \\
\hline Em parte & 04 & 20 \\
\hline Năo sei responder & 20 & 100 \\
\hline Total & & \\
\hline
\end{tabular}




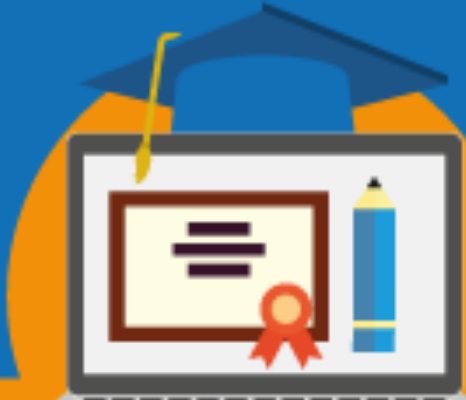

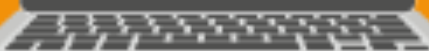

A partir da análise das tabelas 6 e 7, pode-se verificar que a maior parte dos discentes tem conhecimento dos preceitos da dialogicidade de Paulo Freire, e que essa dialogicidade contribui para a $\mathrm{EaD}$, porém pode-se inferir que os discentes de alguma forma entendem a importância do diálogo para a construção do saber, pois ao acumular conhecimento sozinho, o mesmo não participa da construção do mundo. Essas respostas corroboram com os pressupostos de Freire que defende o diálogo para as ações de educação, pois é por meio do diálogo entre os atores envolvidos no EaD que a interação acontece.

A tabela 8 mostra outro aspecto fundamental para $85 \%$ dos discentes o uso das metodologias ativas no curso contribui para a autonomia do aluno e para $15 \%$ dos discentes talvez contribua. No que diz respeito às metodologias ativas, são propostas inovadoras que consistem em educar o aluno para a autonomia, estimulando a reflexão e participação, tornando o ensino mais eficaz. Como diz Berbel (2011) às metodologias ativas têm potencial de despertar a curiosidade à medida que os alunos se inserem na teorização e trazem elementos novos ainda não considerados nas aulas ou na própria perspectiva do professor.

TABELA 8

Utilização da ABP contribui para a autonomia do aluno

\begin{tabular}{|l|c|c|}
\hline Utilizacão da ABP & Quantidade & Porcentagem (\%) \\
\hline Sim & 17 & 85 \\
Näo & 0 & 0 \\
Em parte & 03 & 15 \\
Nắo sei responder & 0 & 0 \\
\hline Total & 20 & 100 \\
\hline
\end{tabular}

\section{CONSIDERAÇÕES FINAIS}

De acordo com os dados obtidos, percebeu-se que a maioria dos discentes acham que algumas ferramentas interativas favorecem a aprendizagem colaborativa e o diálogo, o que não garante que as mesmas por si só contribuem para o êxito dos programas em EaD, sendo 
necessário um planejamento de como serão utilizadas as ferramentas interativas nos cursos em $\mathrm{EaD}$.

Ressalta-se ainda que, por meio dessa interatividade, a autonomia do aluno é estimulada, à medida que haja respeito ao saber que o discente traz e suas experiências anteriores. A maioria dos discentes, tiveram contato anterior com formação/capacitação em $\mathrm{EaD}$, o que já contribuiu para otimização das ações dialógicas, autonomia e troca de sabres.

O estudo demonstrou que o diálogo proporcionou um caminho favorável para efetividade das ações no curso, pois quando a interação é pautada no diálogo, trazendo a proposta de valorizar e socializar o conhecimento trazido pelo aluno como eixo do processo de ensino-aprendizagem estará promovendo a construção participativa do conhecimento.

Sendo assim, o desenvolvimento de habilidades e competências para docência e discência em EaD, é uma necessidade, pois os mesmos serão capazes de utilizarem e potencializarem as ferramentas interativas e estabeleceram uma relação dialógica proporcionando um processo de ensino e aprendizagem, que promova intervenção/construção de um novo mundo.

O uso das metodologias ativas aperfeiçoou a promoção de relações dialógicas, autonomia e troca de saberes. E que para o estabelecimento de relações no espaço virtual, fazse necessário o desenvolvimento de habilidades e competências nos tutores e discentes, pois a concepção dialógica sugere uma construção coletiva do conhecimento, trazendo a responsabilidade a todos os envolvidos, pois as tecnologias por si só não garantem a colaboração e a dialogicidade, elas dependem das relações estabelecidas nos espaços de interatividade. 


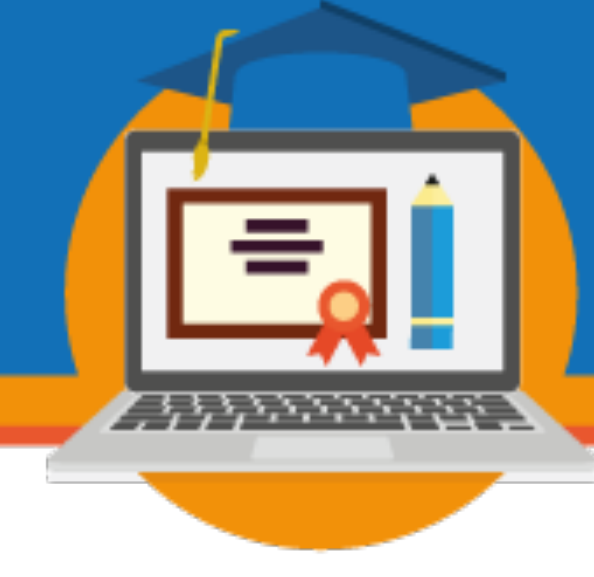

\section{REFERÊNCIAS}

BELLONI, M. L. Educação à distância. Campinas, SP: Autores Associados, 2006.

BERBEL, Neusi Aparecida Navas. As metodologias ativas e a promoção de autonomia dos estudantes. Semina: Ciências Sociais e Humanas, Londrina, v. 32, n. 1, p. 25-40, jan./jun. 2011. FREIRE. Pedagogia da autonomia: saberes necessários à prática educativa. $25^{\mathrm{a}}$ ed. São Paulo: Paz e Terra, 2002.

Extensão ou comunicação? 13 ed. Rio de Janeiro: Paz e Terra, 2006.

FUKS, Hugo ET AL. O modelo de colaboração 3C no ambiente AulaNet. Informática na Educação: Teoria e Prática, Porto Alegre, v. 7, n. 1, p. 25-48, 2004. Disponível em: http://ritv.les.inf.puc-rio.br Acesso em: 19 de maio de 2016.

KENSKI, VM. Tecnologias e ensino presencial e a distância. Campinas, São Paulo: Papirus, 2006.

III SEMINÁRIO DE EDUCAÇÃO A DISTÂNCIA

Diálogos sobre EaD e uso das TDIC na educação: regulamentação em tempos recentes

3 a 6 de novembro de 2020 - Brasília/DF - Online 


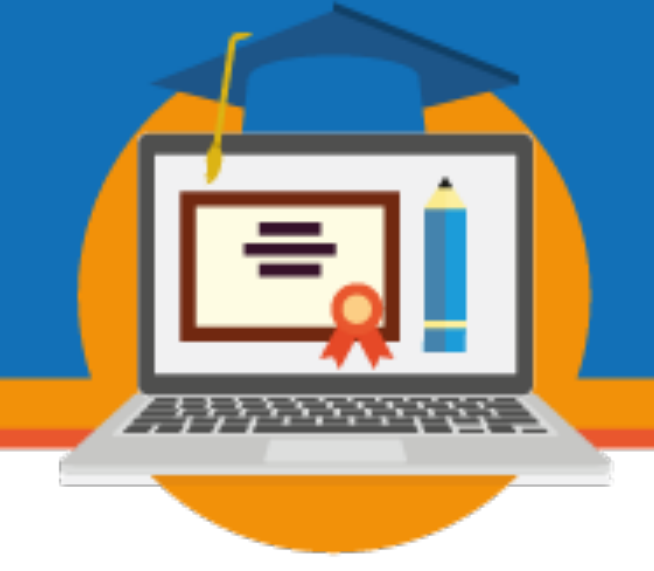

MERCADO, LPL. Dificuldades na Educação à Distância Online. Alagoas: ABED, 2007.

Disponível: http://www.abed.org.br/congresso2007/tc/55200761718PM.pdf. Acesso:

$07 / 05 / 2016$.

RIBAS, IS. Paulo Freire e a EaD: Uma relação próxima e possível. In: Congresso Brasileiro de Educação a Distância - ABED, Curitiba-Paraná- Junho 2010 disponível em: www.abed.org.br/congresso2010. Acessado em 09 de Abril de 2016.

SABBATINI, M. (2013). O pensamento pedagógico de Paulo Freire e a Educação a Distância $(\mathrm{EaD})$ : aproximações entre dialogia, autonomia e emancipação através da Rede. In: Intercom - Sociedade Brasileira de Estudos Interdisciplinares da Comunicação XXXVI Congresso Brasileiro de Ciências da Comunicação - Manaus, AM - 4 a 7/09/2013. Disponível em: https://www.academia.edu/12241730/O pensamento pedag\%C3\%B3gico de Paulo Freire e a Educa\%C3\%A7\%C3\%A3o a Dist\%C3\%A2ncia EaD aproxima\%C3\%A7\%C3\%B5es entre dialogia autonomia e emancipa\%C3\%A7\%C3\%A3o atrav\%C3\%A9s da Rede.

Acessado em: 20 de fevereiro de 2016.

SILVA, Adriane das Neves. Estudo comparativo entre ensino presencial e a distância para educação permanente de profissionais auxiliares e técnicos de enfermagem. [Dissertação de Mestrado] / Adriane das Neves Silva. - Niterói: [s.n.], 2014. 107 f. 